\title{
Neuronal Control of Esophageal Peristalsis and Its Role in Esophageal Disease
}

\author{
K. Nikaki ${ }^{1} \cdot$ A. Sawada ${ }^{1} \cdot$ A. Ustaoglu ${ }^{1} \cdot$ D. Sifrim ${ }^{1}$ \\ Published online: 23 November 2019 \\ (C) The Author(s) 2019
}

\begin{abstract}
Purpose of Review Esophageal peristalsis is a highly sophisticated function that involves the coordinated contraction and relaxation of striated and smooth muscles in a cephalocaudal fashion, under the control of central and peripheral neuronal mechanisms and a number of neurotransmitters. Esophageal peristalsis is determined by the balance of the intrinsic excitatory cholinergic, inhibitory nitrergic and post-inhibitory rebound excitatory output to the esophageal musculature.

Recent Findings Dissociation of the longitudinal and circular muscle contractions characterizes different major esophageal disorders and leads to esophageal symptoms. Provocative testing during esophageal high-resolution manometry is commonly employed to assess esophageal body peristaltic reserve and underpin clinical diagnosis.

Summary Herein, we summarize the main factors that determine esophageal peristalsis and examine their role in major and minor esophageal motility disorders and eosinophilic esophagitis.
\end{abstract}

Keywords Esophageal peristalsis $\cdot$ Esophageal motility disorders

\section{Introduction}

The esophagus transports the swallowed bolus from the pharynx to the stomach and occasionally allows the retrograde flow of stomach contents into the mouth during belching and vomiting [1]. A swallow initiates the coordinated contraction of the circular and longitudinal muscle layers of the esophagus which takes place in the form of primary peristalsis. Esophageal peristalsis has been studied for a long time using several methodologies [2].

\section{Neuronal Control of Peristalsis}

1. Central and Peripheral Regulation

Esophageal peristalsis can be triggered by deglutition (primary peristalsis) and esophageal distention (secondary peri-

This article is part of the Topical Collection on Esophagus

K. Nikaki and A. Sawada are shared first authors.

D. Sifrim

d.sifrim@qmul.ac.uk

1 Wingate Institute of Neurogastroenterology, Blizard Institute, Barts and The London School of Medicine and Dentistry, QMUL, 26 Ashfield Street, Whitechapel, London E1 2AJ, UK stalsis). Primary peristalsis starts immediately with a pharyngeal contraction which pushes the bolus into the esophagus. As the upper esophageal sphincter closes, the esophageal circular muscle contraction starts in the upper esophagus and progresses distally, propelling the bolus into stomach within 8 to $10 \mathrm{~s}$ from the onset of swallowing. The muscular fibers of the proximal third of the esophagus are mostly striated muscle, whereas the distal two thirds of the esophagus contains only smooth muscle with an intermediate transition zone where striated and smooth muscle intermix [3]. Esophageal peristalsis is controlled by central and peripheral neural mechanisms involving extrinsic sympathetic or parasympathetic nerves and myenteric plexus respectively. Furthermore, innervation differs between the striated and the smooth muscle.

\section{Primary Peristalsis}

Control of the Esophageal Striated Muscle The striated muscle is directly innervated by vagal lower motor neurons like other skeletal muscles. Motor end plates are formed between the nerve endings and the striated muscle. The cell bodies of those neurons situated in the vagal retrofacial and ambiguous nuclei fire sequentially, whereby peristalsis is generated aborally. Apart from this extrinsic cholinergic innervation, the esophageal striated muscle portion contains a myenteric plexus with cholinergic and nitrergic neurons. These enteric neurons also 
innervate esophageal striated muscle that might be responsible for inhibitory modulation of striated muscle [4-6]. However, the central nervous system (CNS) plays the main role in controlling the initiation of peristalsis in the proximal esophagus.

Control of Esophageal Smooth Muscle Esophageal smooth muscle contractility is regulated by both central and peripheral control mechanisms in a complex manner. Vagal preganglionic motor nerves from the dorsal motor nucleus (DMN) in the medulla oblongata (MO) synapse with postganglionic motor neurons in the myenteric plexus (Auerbach's plexus), which in turn release neurotransmitters to smooth muscle. It is unknown whether vagal nerves can control esophageal smooth muscle directly bypassing the myenteric plexus. The sympathetic system also innervates the esophageal smooth muscle from intermediolateral columns of the thoracic spine via sympathetic ganglia. Although the sympathetic nerve synapses on the myenteric plexus, it does not affect esophageal motility significantly. The smooth muscle of the esophagus contains a higher number of ganglia in the myenteric plexus compared to the striated muscle [7].

Pre- and post-ganglionic motor neurons can be excitatory or inhibitory [8]. The excitatory pathway comes from the rostral part of the DMN, whereas the inhibitory pathway comes from the caudal part. The swallowing pattern generator in the CNS regulates the activation of these neurons to initiate primary peristalsis. Previous studies have found that the activation of inhibitory nerves occurs simultaneously in the entire esophagus immediately after swallowing (deglutitive inhibition), and that this is followed by peristaltic contraction induced by activation of excitatory neurons in human $[9,10]$. On the other hand, Abrahao et al. [11] showed that the shape of distension by a bolus during peristalsis resembled an American football, with maximal distension at the center and tapering at the two ends, versus the expectation that the relaxed esophageal segment would resemble a cylinder below the bolus. These findings suggest that esophageal relaxation can traverse the esophagus in a manner similar to peristaltic contractions rather than simultaneously as previously suggested in descriptions of deglutitive inhibition.

To generate propagating peristalsis, a proximal esophageal segment needs to contract earlier than a more distal segment at any point along the length of the esophagus. Several factors govern the latency gradient of esophageal contractions including (i) sequential firing of preganglionic efferent vagal nerves, (ii) different discharge latency to firing of vagal efferent fibers [12], (iii) shorter latency of the proximal esophageal muscle compared to the distal esophageal muscle [13, 14], and (iv) gradient of cholinergic and nitrergic nerves along the esophagus [14].

\section{Secondary Peristalsis}

Secondary peristalsis (SP) is initiated by bolus-induced distention of the esophageal wall. In the striated muscle, SP is regulated by a central control mechanism; the distention is transmitted to the CNS via the vagal afferent nerves, and excitatory motor nucleus neurons fire sequentially as in primary peristalsis. In the smooth muscle, SP is triggered by a local reflex; the submucosal plexus (Meisner's plexus) includes afferent (sensory) nerves extending from the esophageal mucosa [15] and connect to myenteric motor nerves via interneurons. Interneurons project orally to synapse to cholinergic excitatory neurons, which initiate a contraction in response to esophageal distention. Other interneurons project distally to synapse on inhibitory nitrergic neurons, which lead to distal relaxation.

\section{Role of Esophageal Longitudinal Muscle Contraction}

Esophageal muscularis is comprised of an inner circular and an outer longitudinal muscle layer [16]. Simultaneous manometry and high-frequency ultrasound studies in humans have shown that the onset, peak, and duration of circular and longitudinal muscle contraction are always in perfect coordination at any given region of the esophagus [17••]. Animal studies suggest that the neural control of these two muscle layers is different [18].

Local simultaneous contraction of the two muscular layers better occludes the esophageal lumen to propel a bolus by stiffening the wall as well as strengthening the contraction via the denser circular muscle fibers. Furthermore, longitudinal muscle contraction leads to thinning of the distal esophageal wall, which is an advantage for bolus accommodation. Axial stretch of the esophagus can induce distal esophageal relaxation. Previous studies have shown that longitudinal muscle contraction can stretch and activate mechanosensitive inhibitory motor neurons to cause nitric oxide-mediated inhibition in the distal esophagus [19]. The direction of stretch may influence the mechanosensitive motor neurons as axial stretch relaxes the lower esophageal sphincter (LES), whereas transverse stretch contracts it $[20,21]$. The stretch-induced activation of inhibitory motor neurons can also participate as a mechanism for deglutitive inhibition apart from swallowinduced discharge of short-latency vagal inhibitory nerves. Elevation of the upper esophageal sphincter by a swallow stretches the esophagus longitudinally, which stimulates inhibitory motor neurons, subsequently relaxing the esophageal body and LES $[17 \bullet \bullet]$.

\section{Esophageal Vagal Sensory Innervation}

Esophageal vagal afferent nerve endings are found in the mucosa, the muscularis propria (intramuscular array [IMA] endings), and the intraganglionic laminar endings (IGLEs). These vagal afferent nerves have their cell bodies in the nodose ganglia located below the jugular foramen. Mucosal afferent 
endings can respond to various stimuli, including mechanical and chemical stimuli. These nerves are not sensitive to intraluminal distention but can detect light touch on the mucosal surface during bolus passage and can be affected by shear forces. In fact, our group has demonstrated the presence of superficial CGRP-positive afferent nerves in human esophageal mucosa $[22,23]$. An IMA is a branching array of vagal axons among smooth muscle layers including the LES. IGLEs are a specialized laminar structure which covers the myenteric ganglia in the muscularis propria. It is assumed that IGLEs perceive passive and active tension [24, 25].

Information about bolus characteristics detected by esophageal afferent nerves is transmitted to the solitary nucleus which affect DMN signals (vago-vagal reflexes) to the smooth esophageal muscles [26]. Furthermore, this information can modify esophageal peristalsis via intramural neuromuscular reflexes. In fact, bolus characteristics can affect the strength and speed of esophageal peristalsis [27-30]. When a large and/or high-viscosity bolus is swallowed, a stronger peristaltic contraction propagates distally and more slowly compared to a contraction triggered by a smaller and/or lower viscosity bolus. Additionally, hot water increases the amplitude of contraction and decreases the duration of contraction, whereas cold water decreases the amplitude of contraction and increases the duration of contraction [31].

Finally, input to the vagal solitary nucleus from the cardiovascular, respiratory, and gastrointestinal systems, as well as the cortex, suggests that esophageal peristalsis is interlinked to changes and disease states from different organs and also to cortically mediated psychological modulation [26].

\section{The LES}

The LES exhibits spontaneous tone [32] and deglutitive LES relaxation/opening is associated with radial effacement and elongation of the LES muscle. LES pressure dynamically reflects the balance of excitatory and inhibitory neural input, and alterations in vagal discharge can result in LES relaxation, with NO being the main neurotransmitter involved in this process [33]. It has been suggested recently that swallowinduced contraction of the longitudinal muscle of the proximal esophageal body can be an important stimulus for LES relaxation [34]. Moreover, neural control of the tonic activity of the crural diaphragm also contributes to the LES pressure [35]. Transient LES relaxations (TLESRs) are a result of vagal inhibitory stimulation during gastric distention [36].

\section{Interstitial Cells of Cajal}

Interstitial cells in the smooth muscle esophagus include fibroblasts, mast cells, macrophages, and interstitial cells of Cajal (ICCs) [37]. ICCs are believed to work as pacemaker cells in the gastrointestinal tract, especially in the stomach, small intestine and colon. In the esophagus, ICCs have been found in smooth muscle and the LES (intramuscular ICC; ICC-IM) [38, 39]. Parasympathetic nerves innervate ICCs as well as smooth muscle, and ICC-IM form a network of nerve endings (IMAs) and esophageal smooth muscle cells within the circular muscle [40]. Therefore, ICC-IM may be associated with esophageal motility and LES relaxation by influencing neurotransmitter release from nerve endings to smooth muscle [39, 41]. Additionally, the network of ICC-IM and IMA may play a role as a stretch receptor [24, 42]. It remains unclear how ICC-IM control esophageal body motility and LES relaxation [43] but achalasia patients show a decrease of both ICCs and neuronal nitric oxide synthase positive cells in the LES [44, 45].

\section{The Neurotransmitters}

Unlike the rest of the gastrointestinal tract where motor events are largely autonomous, the neuromuscular control mechanisms of the esophagus involve coordination between the voluntary and autonomous components of the CNS and the enteric nervous system. The volitional component of the CNS resides in the cerebral cortex, while the autonomous CNS is in the brainstem (3).

In vitro intracellular recordings of the esophageal smooth muscle show that an appropriate stimulus provokes cell membrane hyperpolarization followed by depolarization. The initial drop in the resting membrane potential induces a period of inhibition of contractility or muscle relaxation, followed by muscle contraction [46]. In vivo studies have shown that swallowing initiates immediate hyperpolarization along the esophageal wall, which leads to muscle relaxation [47]. The latency from swallow to contraction (period of hyperpolarization) is controlled by the release of nitric oxide (NO) from inhibitory nerves [48]. However, the initiator of depolarization is less clear. While the release of the excitatory neurotransmitter acetylcholine by cholinergic neurons directly depolarizes the muscle, nitrergic neurons are also thought to generate contraction through their passive rebound from hyperpolarization. Eicosanoids have also been shown to initiate nerve-induced depolarization in the esophageal longitudinal muscles [49].

The balance between cholinergic and nitrergic innervation varies along the esophagus. The latency to contraction in the proximal esophageal smooth muscle was found to be more susceptible to the anticholinergic agent atropine compared to the distal esophagus [14]. Similarly, blockade of nitric oxide synthase inhibits the latency and amplitude of contraction to increase the velocity of peristalsis in the distal smooth muscle of the esophagus more so than the proximal smooth muscle. This highlights a greater cholinergic innervation in the proximal esophagus, while the distal esophagus has greater nitrergic innervation [50]. An imbalance in the inhibitory and excitatory nerve activity often results in the genesis of 
spastic motor disorders of the esophagus. The density of acetylcholinesterase-positive neurons does not change along the esophagus, however, and there are also no anatomical differences in the concentration of nitrergic neurons [51]. Studies have shown that there are no synapses in the pathway of descending hyperpolarization; instead, it is mediated through a single descending neuron [52]. The differences in responses of the esophageal smooth muscle in different regions could be the result of released neurotransmitters. For example, the potassium gradient in the esophagus may contribute to a more positive resting membrane potential in the distal esophagus compared to the proximal [53].

The role of other neurotransmitters in the smooth muscle of the esophagus remains unclear, though there are some data regarding their respective functions. Tachykinins have been found to contribute to the excitatory response of circular smooth muscle generated by electrical stimulation in vitro [54]. Enkephalins have also been found to have a function in the modulation of peristalsis, through either the inhibition or the excitation of various neurotransmitters [55]. Catecholamines and calcitonin gene-related peptide (CGRP) are thought to play an inhibitory role in the control of esophageal contractions [56,57]. Several ion channels expressed on sensory afferent neurons in the esophagus have been shown to modulate gastrointestinal motility $[58,59]$. Secondary peristalsis and distention sensitivity are enhanced by the infusion of transient receptor potential vanilloid receptor 1 (TRPV1) agonist capsaicin, which increases the permeability of primary afferent neuron membranes to $\mathrm{Ca}^{2+}$ [60]. Infusion of the 5$\mathrm{HT}_{4}$ agonist mosapride activates a normal peristaltic reflex by inducing the release of neurotransmitters such as acetylcholine from the postganglionic nerve endings of the myenteric plexus [61]. Conversely, inhibition of acetylcholine release from cholinergic neurons by the purified neurotoxin complex botulinum toxin (botox) injection prevents neuromuscular conduction. This chemical denervation relaxes esophageal smooth muscles and is therefore utilized as an effective and low-risk short-term symptom relief in achalasia and spastic esophageal motility disorders [62]. Opioids inhibit peristalsis through the suppression of neural activity [63]. This effect is thought to be mediated by the inhibition of acetylcholine and nonadrenergic non-cholinergic neurotransmitter release [64].

\section{Failure of Esophageal Neuronal Control in Esophageal Disease}

\section{Achalasia}

Achalasia is defined by impaired deglutitive esophagogastric junction (EGJ) relaxation and absent peristalsis. In type 1 achalasia, there is negligible pressurization within the esophagus; in type 2 achalasia, contractions that do not occlude the lumen result in uniform pressurization; and in type
3 achalasia, spastic contractions (characterized by a shortened distal latency) occur [65]. EGJ outflow obstruction (characterized by an elevated resting pressure of the lower esophageal sphincter with preserved peristalsis in the esophageal body) may be a precursor of achalasia $[66,67]$. It is also believed that there are variant cases of achalasia with preserved peristalsis or partial recovery of peristalsis following resolution of the EGJ obstruction with a myotomy [68], as well as cases with complete or partial EGJ relaxation [69].

Achalasia is thought to be due to an autoimmune process where a cell-mediated and antibody-mediated immune response against an uncertain antigen leads to a myenteric plexopathy [33]. Under normal circumstances, the vagus nerve activates post-ganglionic neurons that orchestrate an ensuing esophageal contraction, and it is precisely these post-ganglionic neurons that are affected in achalasia.

Before the release of a high-resolution manometry (HRM)based classification of esophageal motility disorders (the Chicago Classification), the basic pathophysiological concept in achalasia was that inhibitory myenteric neurons, both in the LES and esophageal body, were predominantly affected. However, it is now known that type 2 achalasia can progress into type 1 achalasia [70], possibly from a cytotoxic attack to the myenteric plexus leading to neuronal apoptosis (type 2), aganglionosis, fibrosis [71], and finally absence of inflammation when the immune target has been exhausted (type 1) [72] Type 3 achalasia is considered a distinct subtype in which there is no neuronal loss but instead an impairment of inhibitory postganglionic function [73] with or without accentuated contractility, possibly as a result of cytokine-induced changes in gene expression [33].

During normal peristalsis, as described above, the longitudinal and circular muscle contract simultaneously, and it is only during TLESRs that the longitudinal muscle contracts independently of the circular. Longitudinal and circular muscle coordination is disrupted in achalasia [74]. More specifically, there is minimal if any longitudinal muscle contraction in type 1 and a strong contraction of the longitudinal muscle in type 2. The latter leads to esophageal shortening and panesophageal pressurization on HRM tracings and appears to be the main mechanism of esophageal emptying in type 2 achalasia (potentially the reason why it has the highest likelihood of response to treatment among the three main achalasia subtypes) [75]. In type 3 achalasia, the circular and longitudinal muscle contraction lack co-ordination. Luminal crosssectional area is largest in type 1 and smallest in type 3 , which is in accordance with the finding that the esophageal wall is thinnest in type 1 and thickest in type 3 achalasia [76]. Finally, prolonged longitudinal muscle contraction is hypothesized to be responsible for the chest pain and heartburn sensation reported in achalasia patients due to the impact of that contraction on esophageal wall blood perfusion [77] while dysphagia may be related to varying bolus flow patterns [76]. 


\section{EGJ Outflow Obstruction}

The Chicago Classification v3.0 (CC v3.0) defines the diagnosis of EGJ outflow obstruction (EGJOO) on the basis of impaired LES relaxation (high median integrated relaxation pressure [IRP]) with intact or weak peristalsis. It also highlights the multiple different etiologies of EGJOO, namely early or incompletely expressed achalasia, infiltrative disease or cancer, vascular obstruction of the distal esophagus, and sliding hiatal or paraesophageal hernia [78]. Impairment of LES relaxation and resultant abnormal bolus clearance [79] are thought to be the reasons for the clinical expression of idiopathic EGJOO. Opioid use should be explored in cases of EGJOO, as the intravenous infusion of opioids at pharmacological doses has been shown to lead to decreased LES relaxation with increased peristaltic wave amplitudes [80]. Opioid-induced esophageal dysmotility can have various manifestations but is most often manometrically consistent with EGJOO or type 3 achalasia $[81 \cdot, 82]$.

\section{Absent contractility}

The diagnosis of absent contractility is made on HRM on the basis of normal EGJ relaxation and $100 \%$ failed peristalsis. In cases of absent contractility with borderline high IRP, the possibility of type 1 achalasia should be considered as well [78]. The pathogenesis of absent contractility remains unclear except in the setting of connective tissue disorders, and specifically scleroderma. In scleroderma, a neuropathy, mediated by abnormalities in the vasa nervorum, is the first stage of esophageal disease development, followed by a myopathy, through ischemia, focal degeneration and atrophy of the muscle layers, and finally esophageal fibrosis [83]. Loss of peristaltic reserve, demonstrated by lack of augmentation and contraction following a multiple rapid swallow (MRS) test, is the most common abnormality observed in patients with scleroderma [84]. MRS during esophageal manometry is commonly employed to assess (a) the inhibitory effect on the esophageal body of frequent, multiple swallows and (b) the generation of a peristaltic wave that is more vigorous than the average of the 10 wet swallows performed during the Chicago classification assessment (MRS DCI/Mean DCI > 1). The latter response is considered an indication of adequate smooth muscle peristaltic reserve [85] but also demonstrates that the efferent and afferent neuronal pathways are active. Other provocative maneuvers, such as the rapid drink challenge, solid swallows, or post-prandial evaluation, are used to further characterize cases of dysphagia [86-88] and postprandial [89•] syndromes where bolus clearance and reproduction of symptoms are of interest.

\section{Distal Esophageal Spasm}

The CC v3.0 defines DES as the presence of two or more premature contractions, defined as a distal latency (DL) of $<$ $4.5 \mathrm{~s}$ [78]. There is an argument that a subgroup of patients with a normal DL might still have DES on the basis of rapid contractions as defined by contractile front velocity, though this latter manometric parameter has been de-emphasized in the Chicago Classification's most recent iteration [90]. In patients with DES, there tends to be evidence of impaired deglutitive inhibition in the esophageal body during MRS [91].

There is a neural gradient with an increasing proportion of inhibitory ganglionic neurons progressing distally, such that it creates a progressively prolonged deglutitive inhibition from the proximal to the distal end of the esophagus; this prolonged inhibition is expressed on HRM tracings as the DL [92]. Experimental NO depletion induces simultaneous contractions in healthy volunteers [93], while administration of NO donors increases the DL [94]. The increase in esophageal smooth muscle thickness noted in DES may be a primary event in the pathogenesis of this entity [95] or a secondary result of the lack of inhibitory innervation [96]. Biopsies obtained during POEM for the treatment if DES have shown atrophy and fibrosis of the muscularis propria layer as well as a decreased number of ICCs [97].

\section{Hypercontractile (Jackhammer) Esophagus}

The definition of hypercontractile esophagus or Jackhammer esophagus is presence of at least $20 \%$ of highamplitude contractions, with a distal contractile integral (DCI)

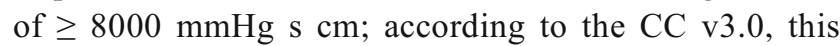
hypercontractility may involve or be localized primarily to the LES $[78,98]$. It is hypothesized that the pathophysiology of hypercontractile esophagus is related to an excess of cholinergic drive and temporal asynchrony of circular and longitudinal muscle contractions [99]. Hypercontractility can also be associated with EGJ outflow obstruction [100] and increased muscle thickness [101]. In certain patients with hypercontractile esophagus, MRS testing will demonstrate abnormal deglutitive inhibition; in others, provocative testing with the rapid drink challenge (RDC) will demonstrate incomplete LES relaxation [102].

\section{Ineffective Esophageal Motility and Hypomotility}

Ineffective esophageal motility (IEM) is a minor motility disorder in CC v3.0 [78] and can present in healthy, asymptomatic individuals (17\%) [103]. Based on HRM, IEM is defined as absent (DCI: distal contractile integral $<100 \mathrm{mmHg} \mathrm{s}$ $\mathrm{cm}$ ) or failed peristalsis (DCI $100-450 \mathrm{mmHg} \mathrm{s} \mathrm{cm}$ ) on $\geq 50 \%$ of wet swallows [104]. The pathophysiology of IEM is 
multifactorial, and any factors affecting peristalsis, bolus transit, and clearance may be involved. In physiologic terms, IEM is the end result of defects in either (a) the initial stretching of the esophageal muscle that fires off a mechanosensitive pathway for the initiation of peristalsis, (b) the intrinsic esophageal contractility, or (c) the "afterload" resistance that the contraction should overcome [105].

Failed peristalsis has a clear predictive value in reflux burden $[106,107]$ and is associated with impaired bolus clearance and symptomatic dysphagia [108], although the correlation between IEM and symptoms is not perfect [107, 109], indicating that symptoms are not specific for IEM. IEM is common in gastroesophageal reflux disease (GERD) [110], and its prevalence increases with the severity of esophagitis (25\% in mild esophagitis and almost 50\% in severe esophagitis) [111-113]. Lack of augmentation of esophageal body contraction during the MRS is currently used to identify patients with poor peristaltic reserve who are therefore at risk of developing post-operative dysphagia following anti-reflux surgery [114••]. Interestingly, IEM can either persist following antireflux surgery, resolve or appear as a "new" finding [115].

\section{Eosinophilic Esophagitis}

In eosoniphilic esophagitis (EoE), there is a dissociation in the contraction of the longitudinal and circular muscle during primary peristalsis demonstrated by simultaneous ultrasound and manometric measurements [116]. It is hypothesized that either the eosinophilic infiltration of muscle layers [117, 118] or the occurrence of tissue remodeling and fibrosis is responsible for the esophageal dysmotility observed $[119,120]$. The commonest abnormality observed on HRM in cases of EoE is panesophageal pressurization [121]. With specific attention to pediatric patients with EoE, prolonged esophageal manometry shows an increased number of isolated and high-amplitude contractions alongside ineffective esophageal motility during fasting and meal periods [122].

\section{Conclusions and Future Directions for Research}

There are multiple levels of neuronal control in esophageal peristalsis, which under normal circumstances requires coordinated function amongst various central and peripheral mechanisms, neurotransmitters, striated and smooth muscle contraction and relaxation, and esophageal sensory inputs. Overall, esophageal peristalsis is a finely tuned mechanism that has been the subject of substantial research interest, though with several clinically relevant details yet to be elucidated, including the generation of esophageal symptoms and the identification of disease-specific therapeutic targets.

\section{Compliance with Ethical Standards}

Conflict of Interest The authors declare that they have no conflict of interest.

Human and Animal Rights and Informed Consent This article does not contain any studies with human or animal subjects performed by any of the authors.

Open Access This article is distributed under the terms of the Creative Commons Attribution 4.0 International License (http:// creativecommons.org/licenses/by/4.0/), which permits unrestricted use, distribution, and reproduction in any medium, provided you give appropriate credit to the original author(s) and the source, provide a link to the Creative Commons license, and indicate if changes were made.

\section{References}

Papers of particular interest, published recently, have been highlighted as:

- Of importance

- Of major importance

1. Vantrappen G, Hellemans J, Debray C. Diseases of the esophagus. Berlin; New York: Springer-Verlag; 1974.

2. Goyal RK, Chaudhury A. Physiology of normal esophageal motility. J Clin Gastroenterol. 2008;42(5):610-9.

3. Liebermann-Meffert D. Muscular equivalent of the lower esophageal sphincter. Gastroenterology. 1979;76(1):31-8.

4. Storr M, Geisler F, Neuhuber WL, Schusdziarra V, Allescher HD. Characterization of vagal input to the rat esophageal muscle. Auton Neurosci. 2001;91(1-2):1-9.

5. Kallmünzer B, Sörensen B, Neuhuber WL, Wörl J. Enteric coinnervation of striated muscle fibres in human oesophagus. Neurogastroenterol Motil. 2008;20(6):597-610.

6. Neuhuber WL, Wörl J. Enteric co-innervation of striated muscle in the esophagus: still enigmatic? Histochem Cell Biol. 2016;146(6):721-35.

7. Christensen J, Stiles MJ, Rick GA, Sutherland J. Comparative anatomy of the myenteric plexus of the distal colon in eight mammals. Gastroenterology. 1984;86(4):706-13.

8. Chang HY, Mashimo H, Goyal RK. Musings on the wanderer: what's new in our understanding of vago-vagal reflex? IV. Current concepts of vagal efferent projections to the gut. Am J Physiol Gastrointest Liver Physiol. 2003;284(3):G357-66.

9. Sifrim D, Janssens J, Vantrappen G. A wave of inhibition precedes primary peristaltic contractions in the human esophagus. Gastroenterology. 1992;103(3):876-82.

10. Sifrim D, Janssens J, Vantrappen G. Failing deglutitive inhibition in primary esophageal motility disorders. Gastroenterology. 1994;106(4):875-82.

11. Abrahao L Jr, Bhargava V, Babaei A, Ho A, Mittal RK. Swallow induces a peristaltic wave of distension that marches in front of the peristaltic wave of contraction. Neurogastroenterol Motil. 2011;23(3):201-7 e110.

12. Gidda JS, Goyal RK. Swallow-evoked action potentials in vagal preganglionic efferents. J Neurophysiol. 1984;52(6):1169-80.

13. Sarna SK, Daniel EE, Waterfall WE. Myogenic and neural control systems for esophageal motility. Gastroenterology. 1977;73(6): $1345-52$. 
14. Crist J, Gidda JS, Goyal RK. Intramural mechanism of esophageal peristalsis: roles of cholinergic and noncholinergic nerves. Proc Natl Acad Sci U S A. 1984;81(11):3595-9.

15. Kumar D, Phillips SF. Human myenteric plexus: confirmation of unfamiliar structures in adults and neonates. Gastroenterology. 1989;96(4):1021-8.

16. Sivarao DV, Goyal RK. Functional anatomy and physiology of the upper esophageal sphincter. Am J Med. 2000;108(Suppl 4a):27s$37 \mathrm{~s}$.

17.•- Mittal RK. Regulation and dysregulation of esophageal peristalsis by the integrated function of circular and longitudinal muscle layers in health and disease. Am J Physiol Gastrointest Liver Physiol. 2016;311(3):G431-43. Dissociation of the longitudinal and circular muscle contractions leads to oesophageal symptoms.

18. Christensen J, Lund GF. Esophageal responses to distension and electrical stimulation. J Clin Invest. 1969;48(2):408-19.

19. Muinuddin A, Paterson WG. Initiation of distension-induced descending peristaltic reflex in opossum esophagus: role of muscle contractility. Am J Physiol Gastrointest Liver Physiol. 2001;280(3):G431-8.

20. Jiang Y, Bhargava V, Mittal RK. Mechanism of stretch-activated excitatory and inhibitory responses in the lower esophageal sphincter. Am J Physiol Gastrointest Liver Physiol. 2009;297(2): G397-405.

21. Dong H, Jiang Y, Dong J, Mittal RK. Inhibitory motor neurons of the esophageal myenteric plexus are mechanosensitive. Am J Phys Cell Physiol. 2015;308(5):C405-13.

22. Woodland P, Aktar R, Mthunzi E, et al. Distinct afferent innervation patterns within the human proximal and distal esophageal mucosa. Am J Physiol Gastrointest Liver Physiol. 2015;308(6): G525-31.

23. Woodland P, Shen Ooi JL, Grassi F, et al. Superficial esophageal mucosal afferent nerves may contribute to reflux hypersensitivity in nonerosive reflux disease. Gastroenterology. 2017;153(5): 1230-9.

24. Phillips RJ, Powley TL. Tension and stretch receptors in gastrointestinal smooth muscle: re-evaluating vagal mechanoreceptor electrophysiology. Brain Res Brain Res Rev. 2000;34(1-2):1-26.

25. Zagorodnyuk VP, Brookes SJ. Transduction sites of vagal mechanoreceptors in the guinea pig esophagus. J Neurosci. 2000;20(16):6249-55.

26. Chen JH. Ineffective esophageal motility and the vagus: current challenges and future prospects. Clin Exp Gastroenterol. 2016;9: 291-9.

27. Dooley CP, Schlossmacher B, Valenzuela JE. Effects of alterations in bolus viscosity on esophageal peristalsis in humans. Am J Phys. 1988;254(1 Pt 1):G8-11.

28. Xiao Y, Read A, Nicodème F, Roman S, Kahrilas PJ, Pandolfino JE. The effect of a sitting vs supine posture on normative esophageal pressure topography metrics and Chicago classification diagnosis of esophageal motility disorders. Neurogastroenterol Motil. 2012;24(10):e509-16.

29. Choi YJ, Park MI, Park SJ, et al. The effect of water bolus temperature on esophageal motor function as measured by highresolution manometry. Neurogastroenterol Motil. 2014;26(11): 1628-34.

30. do Carmo GC, Jafari J, Sifrim D, de Oliveira RB. Normal esophageal pressure topography metrics for data derived from the Sandhill-Unisensor high-resolution manometry assembly in supine and sitting positions. Neurogastroenterol Motil. 2015;27(2): 285-92.

31. Winship DH, Viegas de Andrade SR, Zboralske FF. Influence of bolus temperature on human esophageal motor function. J Clin Invest. 1970;49(2):243-50.
32. Christensen J, Conklin JL, Freeman BW. Physiologic specialization at esophagogastric junction in three species. Am J Phys. 1973;225(6):1265-70.

33. Kahrilas PJ, Boeckxstaens G. The spectrum of achalasia: lessons from studies of pathophysiology and high-resolution manometry. Gastroenterology. 2013;145(5):954-65.

34. Dogan I, Bhargava V, Liu J, Mittal RK. Axial stretch: A novel mechanism of the lower esophageal sphincter relaxation. Am J Physiol Gastrointest Liver Physiol. 2007;292(1):G329-34.

35. Young RL, Page AJ, Cooper NJ, Frisby CL, Blackshaw LA. Sensory and motor innervation of the crural diaphragm by the vagus nerves. Gastroenterology. 2010;138(3):1091-101.e10911095 .

36. Mittal RK, Holloway RH, Penagini R, Blackshaw LA, Dent J. Transient lower esophageal sphincter relaxation. Gastroenterology. 1995;109(2):601-10.

37. Sanders KM, Ward SM, Koh SD. Interstitial cells: regulators of smooth muscle function. Physiol Rev. 2014;94(3):859-907.

38. Christensen J, Rick GA, Soll DJ. Intramural nerves and interstitial cells revealed by the Champy-Maillet stain in the opossum esophagus. J Auton Nerv Syst. 1987;19(2):137-51.

39. Daniel EE, Posey-Daniel V. Neuromuscular structures in opossum esophagus: role of interstitial cells of Cajal. Am J Phys. 1984;246(3 Pt 1):G305-15.

40. Berezin I, Daniel EE, Huizinga JD. Ultrastructure of interstitial cells of Cajal in the canine distal esophagus. Can J Physiol Pharmacol. 1994;72(9):1049-59.

41. Burns AJ, Lomax AE, Torihashi S, Sanders KM, Ward SM. Interstitial cells of Cajal mediate inhibitory neurotransmission in the stomach. Proc Natl Acad Sci U S A. 1996;93(21):12008-13.

42. Powley TL, Wang XY, Fox EA, Phillips RJ, Liu LW, Huizinga JD. Ultrastructural evidence for communication between intramuscular vagal mechanoreceptors and interstitial cells of Cajal in the rat fundus. Neurogastroenterol Motil. 2008;20(1):69-79.

43. Sivarao DV, Mashimo HL, Thatte HS, Goyal RK. Lower esophageal sphincter is achalasic in nNOS(-/-) and hypotensive in W/W(v) mutant mice. Gastroenterology. 2001;121(1):34-42.

44. Gockel I, Bohl JR, Eckardt VF, Junginger T. Reduction of interstitial cells of Cajal (ICC) associated with neuronal nitric oxide synthase (n-NOS) in patients with achalasia. Am J Gastroenterol. 2008;103(4):856-64.

45. Liu ZQ, Chen WF, Wang Y, et al. Mast cell infiltration associated with loss of interstitial cells of Cajal and neuronal degeneration in achalasia. Neurogastroenterol Motil. 2019;31(5):e13565.

46. Decktor DL, Ryan JP. Transmembrane voltage of opossum esophageal smooth muscle and its response to electrical stimulation of intrinsic nerves. Gastroenterology. 1982;82(2):301-8.

47. Rattan S, Gidda JS, Goyal RK. Membrane potential and mechanical responses of the opossum esophagus to vagal stimulation and swallowing. Gastroenterology. 1983;85(4):922-8.

48. Yamato S, Spechler SJ, Goyal RK. Role of nitric oxide in esophageal peristalsis in the opossum. Gastroenterology. 1992;103(1): 197-204.

49. Saha JK, Hirano I, Goyal RK. Biphasic effect of SNP on opossum esophageal longitudinal muscle: involvement of cGMP and eicosanoids. Am J Phys. 1993;265(2 Pt 1):G403-7.

50. Xue S, Valdez D, Collman PI, Diamant NE. Effects of nitric oxide synthase blockade on esophageal peristalsis and the lower esophageal sphincter in the cat. Can J Physiol Pharmacol. 1996;74(11): 1249-57.

51. Seelig LL Jr, Doody P, Brainard L, Gidda JS, Goyal RK. Acetylcholinesterase and choline acetyltransferase staining of neurons in the opossum esophagus. Anat Rec. 1984;209(1): 125-30.

52. Paterson WG, Indrakrishnan B. Descending peristaltic reflex in the opossum esophagus. Am J Phys. 1995;269(2 Pt 1):G219-24. 
53. Schulze K, Conklin JL, Christensen J. A potassium gradient in smooth muscle segment of the opossum esophagus. Am J Phys. 1977;232(3):E270-3.

54. Krysiak PS, Preiksaitis HG. Tachykinins contribute to nervemediated contractions in the human esophagus. Gastroenterology. 2001;120(1):39-48.

55. Stacher G, Bauer P, Steinringer H, Schmierer G, Langer B, Winklehner S. Dose-related effects of the synthetic metenkephalin analogue FK 33-824 on esophageal motor activity in healthy humans. Gastroenterology. 1982;83(5):1057-61.

56. Cohen S, Green F. Force-velocity characteristics of esophageal muscle: effect of acetylcholine and norepinephrine. Am J Phys. 1974;226(5):1250-6

57. Rattan S, Gonnella P, Goyal RK. Inhibitory effect of calcitonin gene-related peptide and calcitonin on opossum esophageal smooth muscle. Gastroenterology. 1988;94(2):284-93.

58. Holzer P. Acid-sensitive ion channels in gastrointestinal function. Curr Opin Pharmacol. 2003;3(6):618-25.

59. Lee KJ, Vos R, Janssens J, Tack J. Differential effects of baclofen on lower oesophageal sphincter pressure and proximal gastric motility in humans. Aliment Pharmacol Ther. 2003;18(2):199-207.

60. Bourinet E, Altier C, Hildebrand ME, Trang T, Salter MW, Zamponi GW. Calcium-permeable ion channels in pain signaling. Physiol Rev. 2014;94(1):81-140.

61. Grider JR. Neurotransmitters mediating the intestinal peristaltic reflex in the mouse. J Pharmacol Exp Ther. 2003;307(2):460-7.

62. Vanuytsel T, Bisschops R, Farre R, et al. Botulinum toxin reduces dysphagia in patients with nonachalasia primary esophageal motility disorders. Clin Gastroenterol Hepatol. 2013;11(9):11151121.e1112.

63. Khansari M, Sohrabi M, Zamani F. The useage of opioids and their adverse effects in gastrointestinal practice: a review. Middle East J Dig Dis. 2013;5(1):5-16.

64. Holzer P. Opioids and opioid receptors in the enteric nervous system: from a problem in opioid analgesia to a possible new prokinetic therapy in humans. Neurosci Lett. 2004;361(1-3): 192-5.

65. Pandolfino JE, Kahrilas PJ. AGA technical review on the clinical use of esophageal manometry. Gastroenterology. 2005;128(1): 209-24.

66. van Hoeij FB, Smout AJ, Bredenoord AJ. Characterization of idiopathic esophagogastric junction outflow obstruction. Neurogastroenterol Motil. 2015;27(9):1310-6.

67. Perez-Fernandez MT, Santander C, Marinero A, BurgosSantamaria D, Chavarria-Herbozo C. Characterization and follow-up of esophagogastric junction outflow obstruction detected by high resolution manometry. Neurogastroenterol Motil. 2016;28(1):116-26.

68. Roman S, Kahrilas PJ, Mion F, et al. Partial recovery of peristalsis after myotomy for achalasia: more the rule than the exception. JAMA Surg. 2013;148(2):157-64.

69. Hirano I, Tatum RP, Shi G, Sang Q, Joehl RJ, Kahrilas PJ. Manometric heterogeneity in patients with idiopathic achalasia. Gastroenterology. 2001;120(4):789-98.

70. Sodikoff JB, Lo AA, Shetuni BB, Kahrilas PJ, Yang GY, Pandolfino JE. Histopathologic patterns among achalasia subtypes. Neurogastroenterol Motil. 2016;28(1):139-45.

71. Nakajima N, Sato H, Takahashi K, et al. Muscle layer histopathology and manometry pattern of primary esophageal motility disorders including achalasia. Neurogastroenterol Motil. 29: e12968. https://doi.org/10.1111/nmo.12968.

72. Goldblum JR, Rice TW, Richter JE. Histopathologic features in esophagomyotomy specimens from patients with achalasia. Gastroenterology. 1996;111(3):648-54.

73. Bruley des Varannes S, Chevalier J, Pimont S, et al. Serum from achalasia patients alters neurochemical coding in the myenteric plexus and nitric oxide mediated motor response in normal human fundus. Gut. 2006;55(3):319-26.

74. Hong SJ, Bhargava V, Jiang Y, Denboer D, Mittal RK. A unique esophageal motor pattern that involves longitudinal muscles is responsible for emptying in achalasia esophagus. Gastroenterology. 2010;139(1):102-11.

75. Mittal RK, Hong SJ, Bhargava V. Longitudinal muscle dysfunction in achalasia esophagus and its relevance. J Neurogastroenterol Motil. 2013;19(2):126-36.

76. Park S, Zifan A, Kumar D, Mittal RK. Genesis of esophageal pressurization and bolus flow patterns in patients with achalasia esophagus. Gastroenterology. 2018;155(2):327-36.

77. Jiang Y, Bhargava V, Kim YS, Mittal RK. Esophageal wall blood perfusion during contraction and transient lower esophageal sphincter relaxation in humans. Am J Physiol Gastrointest Liver Physiol. 2012;303(5):G529-35.

78. Kahrilas PJ, Bredenoord AJ, Fox M, et al. The Chicago classification of esophageal motility disorders, v3.0. Neurogastroenterol Motil. 2015;27(2):160-74.

79. Zheng E, Gideon RM, Sloan J, Katz PO. Esophagogastric junction outflow obstruction is often associated with coexistent abnormal esophageal body motility and abnormal bolus transit. Dis Esophagus. 2017;30(10):1-4.

80. Dowlatshahi K, Evander A, Walther B, Skinner DB. Influence of morphine on the distal oesophagus and the lower oesophageal sphincter-a manometric study. Gut. 1985;26(8):802-6.

81. Ratuapli SK, Crowell MD, DiBaise JK, et al. Opioid-induced esophageal dysfunction (OIED) in patients on chronic opioids. Am J Gastroenterol. 2015;110(7):979-84. Opioid use lead to obstructive oesophageal symptoms and abnormal manometric findings.

82. Babaei A, Szabo A, Shad S, Massey BT. Chronic daily opioid exposure is associated with dysphagia, esophageal outflow obstruction, and disordered peristalsis. Neurogastroenterol Motil. 2019:e13601. https://doi.org/10.1111/nmo.13601.

83. Sallam H, McNearney TA, Chen JD. Systematic review: pathophysiology and management of gastrointestinal dysmotility in systemic sclerosis (scleroderma). Aliment Pharmacol Ther. 2006;23(6):691-712.

84. Carlson DA, Crowell MD, Kimmel JN, et al. Loss of Peristaltic Reserve, Determined by multiple rapid swallows, is the most frequent esophageal motility abnormality in patients with systemic sclerosiS. Clin Gastroenterol Hepatol. 2016;14(10):1502-6.

85. Sweis R, Heinrich H, Fox M. Variation in esophageal physiology testing in clinical practice: Results from an international survey. Neurogastroenterol Motil. 2018; 30:e13215. https://doi.org/10. 1111/nmo.13215.

86. Ang D, Misselwitz B, Hollenstein M, et al. Diagnostic yield of high-resolution manometry with a solid test meal for clinically relevant, symptomatic oesophageal motility disorders: serial diagnostic study. Lancet Gastroenterol Hepatol. 2017;2(9):654-61.

87. Woodland P, Gabieta-Sonmez S, Arguero J, et al. $200 \mathrm{~mL}$ Rapid drink challenge during high-resolution manometry best predicts objective esophagogastric junction obstruction and correlates with symptom severity. J Neurogastroenterol Motil. 2018;24(3):410-4.

88. Wang YT, Tai LF, Yazaki E, et al. Investigation of dysphagia after antireflux surgery by high-resolution manometry: impact of multiple water swallows and a solid test meal on diagnosis, management, and clinical outcome. Clin Gastroenterol Hepatol. 2015;13(9):1575-83.

89. Yadlapati R, Tye M, Roman S, Kahrilas PJ, Ritter K, Pandolfino JE. Postprandial high-resolution impedance manometry identifies mechanisms of nonresponse to proton pump inhibitors. Clin Gastroenterol Hepatol. 2018;16(2):211-218.e211. Rumination syndrome and supragastric belching are major causes of non-response to PPIs. 
90. De Schepper HU, Ponds FA, Oors JM, Smout AJ, Bredenoord AJ. Distal esophageal spasm and the Chicago classification: is timing everything? Neurogastroenterol Motil. 2016;28(2):260-5.

91. Sifrim D, Jafari J. Deglutitive inhibition, latency between swallow and esophageal contractions and primary esophageal motor disorders. J Neurogastroenterol Motil. 2012;18(1):6-12.

92. Behar J, Biancani P. Pathogenesis of simultaneous esophageal contractions in patients with motility disorders. Gastroenterology. 1993;105(1):111-8.

93. Murray JA, Ledlow A, Launspach J, Evans D, Loveday M, Conklin JL. The effects of recombinant human hemoglobin on esophageal motor functions in humans. Gastroenterology. 1995;109(4):1241-8.

94. Konturek JW, Gillessen A, Domschke W. Diffuse esophageal spasm: a malfunction that involves nitric oxide? Scand J Gastroenterol. 1995;30(11):1041-5.

95. Pehlivanov N, Liu J, Kassab GS, Puckett JL, Mittal RK. Relationship between esophageal muscle thickness and intraluminal pressure: an ultrasonographic study. Am J Physiol Gastrointest Liver Physiol. 2001;280(6):G1093-8.

96. Mashimo H, Kjellin A, Goyal RK. Gastric stasis in neuronal nitric oxide synthase-deficient knockout mice. Gastroenterology. 2000;119(3):766-73.

97. Takahashi K, Sato H, Sato Y, et al. Education and Imaging. Gastroenterology: histopathological investigation of distal esophageal spasm (DES) using per-oral endoscopic myotomy (POEM). J Gastroenterol Hepatol. 2015;30(7):1113.

98. Herregods TV, Smout AJ, Ooi JL, Sifrim D, Bredenoord AJ. Jackhammer esophagus: observations on a European cohort. Neurogastroenterol Motil. 29: e12975. https://doi.org/10.1111/ nmo.12975.

99. Jung HY, Puckett JL, Bhalla V, et al. Asynchrony between the circular and the longitudinal muscle contraction in patients with nutcracker esophagus. Gastroenterology. 2005;128(5):1179-86.

100. Gyawali CP, Kushnir VM. High-resolution manometric characteristics help differentiate types of distal esophageal obstruction in patients with peristalsis. Neurogastroenterol Motil. 2011;23(6): 502-e197.

101. Dogan I, Puckett JL, Padda BS, Mittal RK. Prevalence of increased esophageal muscle thickness in patients with esophageal symptoms. Am J Gastroenterol. 2007;102(1):137-45.

102. Mauro A, Quader F, Tolone S, et al. Provocative testing in patients with jackhammer esophagus: evidence for altered neural control. Am J Physiol Gastrointest Liver Physiol. 2019;316(3):G397g403.

103. Hollenstein M, Thwaites P, Butikofer S, et al. Pharyngeal swallowing and oesophageal motility during a solid meal test: a prospective study in healthy volunteers and patients with major motility disorders. Lancet Gastroenterol Hepatol. 2017;2(9):644 53.

104. Xiao Y, Kahrilas PJ, Kwasny MJ, et al. High-resolution manometry correlates of ineffective esophageal motility. Am J Gastroenterol. 2012;107(11):1647-54.

105. Gyawali CP, Sifrim D, Carlson DA, et al. Ineffective esophageal motility: concepts, future directions, and conclusions from the Stanford 2018 symposium. Neurogastroenterol Motil. 2019: e13584. https://doi.org/10.1111/nmo.13584.

106. Rengarajan A, Bolkhir A, Gor P, Wang D, Munigala S, Gyawali CP. Esophagogastric junction and esophageal body contraction metrics on high-resolution manometry predict esophageal acid burden. Neurogastroenterol Motil. 2018;30(5):e13267.
107. Shetler KP, Bikhtii S, Triadafilopoulos G. Ineffective esophageal motility: clinical, manometric, and outcome characteristics in patients with and without abnormal esophageal acid exposure. Dis Esophagus. 2017;30(6):1-8

108. Jain A, Baker JR, Chen JW. In ineffective esophageal motility, failed swallows are more functionally relevant than weak swallows. Neurogastroenterol Motil. 2018;30(6):e13297.

109. Xiao Y, Kahrilas PJ, Nicodeme F, Lin Z, Roman S, Pandolfino JE. Lack of correlation between HRM metrics and symptoms during the manometric protocol. Am J Gastroenterol. 2014;109(4):5216.

110. Chan WW, Haroian LR, Gyawali CP. Value of preoperative esophageal function studies before laparoscopic antireflux surgery. Surg Endosc. 2011;25(9):2943-9.

111. Kahrilas PJ, Dodds WJ, Hogan WJ, Kern M, Arndorfer RC, Reece A. Esophageal peristaltic dysfunction in peptic esophagitis. Gastroenterology. 1986;91(4):897-904.

112. Wu JC, Cheung CM, Wong VW, Sung JJ. Distinct clinical characteristics between patients with nonerosive reflux disease and those with reflux esophagitis. Clin Gastroenterol Hepatol. 2007;5(6):690-5.

113. Savarino E, Gemignani L, Pohl D, et al. Oesophageal motility and bolus transit abnormalities increase in parallel with the severity of gastro-oesophageal reflux disease. Aliment Pharmacol Ther. 2011;34(4):476-86.

114.• Shaker A, Stoikes N, Drapekin J, Kushnir V, Brunt LM, Gyawali CP. Multiple rapid swallow responses during esophageal highresolution manometry reflect esophageal body peristaltic reserve. Am J Gastroenterol. 2013;108(11):1706-12. Provocative testing with multiple rapid swallowing assesses the peristaltic reserve and predicts post-operative dysphagia following anti-reflux surgery.

115. Mello MD, Shriver AR, Li Y, Patel A, Gyawali CP. Ineffective esophageal motility phenotypes following fundoplication in gastroesophageal reflux disease. Neurogastroenterol Motil. 2016;28(2):292-8.

116. Korsapati H, Babaei A, Bhargava V, Dohil R, Quin A, Mittal RK. Dysfunction of the longitudinal muscles of the oesophagus in eosinophilic oesophagitis. Gut. 2009;58(8):1056.

117. Stevoff C, Rao S, Parsons W, Kahrilas PJ, Hirano I. EUS and histopathologic correlates in eosinophilic esophagitis. Gastrointest Endosc. 2001;54(3):373-7.

118. Fox VL, Nurko S, Teitelbaum JE, Badizadegan K, Furuta GT. High-resolution EUS in children with eosinophilic "allergic" esophagitis. Gastrointest Endosc. 2003;57(1):30-6.

119. Chehade M, Sampson HA, Morotti RA, Magid MS. Esophageal subepithelial fibrosis in children with eosinophilic esophagitis. J Pediatr Gastroenterol Nutr. 2007;45(3):319-28.

120. Aceves SS, Newbury RO, Dohil R, Bastian JF, Broide DH. Esophageal remodeling in pediatric eosinophilic esophagitis. J Allergy Clin Immunol. 2007;119(1):206-12.

121. Martin Martin L, Santander C, Lopez Martin MC, et al. Esophageal motor abnormalities in eosinophilic esophagitis identified by high-resolution manometry. J Gastroenterol Hepatol. 2011;26(9):1447-50.

122. Nurko S, Rosen R, Furuta GT. Esophageal dysmotility in children with eosinophilic esophagitis: a study using prolonged esophageal manometry. Am J Gastroenterol. 2009;104(12):3050-7.

Publisher's Note Springer Nature remains neutral with regard to jurisdictional claims in published maps and institutional affiliations. 